\title{
LA IMPORTANCIA DEL TESTAMENTO EN LA (AUTO)REPRESENTACIÓN DE LA MUJER NOBLE DE LA EDAD MODERNA. MARÍA DE GUEVARA, CONDESA DE ESCALANTE Y SU PROYECCIÓN HISTÓRICA
}

NIEVES ROMERO-DÍAZ

Mount Holyoke College rdiaz@mtholyoke.edu

RESUMEN: Este artículo analiza las últimas voluntades de María de Guevara, Condesa de Escalante, en el contexto del género testamentario de la edad moderna española. En el testamento de 1678, junto con su codicilo de 1681y la memoria pre-mortem de 1683, Guevara se posiciona políticamente desde una sólida consciencia social y de género sexual y consigue dejar una impronta personal e histórica para el futuro. Por su papel custodio, esta documentación se convierte así en una memoria de su vida en la que se distingue claramente entre el yo que se (auto)representa y aquellos que, siguiendo sus mandas y disposiciones, la recordarán después de su muerte.

PALABRAS CLAVE: María de Guevara, Condesa de Escalante; testamento, codicilo, memoria pre-mortem; agencia; (auto)representación; memoria. 


\section{THE IMPORTANCE OF WILLS FOR EARLY MODERN NOBLE- WOMEN'S (SELF)REPRESENTATION. María of Guevara, Countess of Escalante and her historical projection}

ABSTRACT: This essay analyzes the last will and testament of María de Guevara, Countess of Escalante, in the context of the testamentary genre of early modern Spain. In the will of 1678 , along with the 1681 codicil and the 1683 pre mortem [last disposition] document, Guevara politically positions herself from a solid social and gender consciousness and is able to leave a personal and historical mark for the future. For its custodial role, her last will becomes then a memory of her life in which a clear distinction is made between the ' $\mathrm{I}$ ' that (self)represents and those who, following her dispositions and requests, will remember her after her death.

KEYWORDS: María of Guevara, Countess of Escalante; will, codicil and pre-mortem report; agency; (self)representation; remembrance.

$\mathrm{D}$ de la publicación de la semblanza biográfica que Manuel Serrano y Sanz publicó sobre María de Guevara, Condesa de Escalante, en 1903 como parte de sus Apuntes de escritoras españolas, la presencia de esta condesa en el ámbito académico ha ido aumentando sobre todo en los últimos años. ${ }^{1}$ Arbitrista, nostálgica e idealista, conservadora pero al mismo tiempo paradójicamente subversiva, luchadora y desafiante, son algunas de las cualidades que se asocian a María de Guevara, quien, con su vida y su escritura, crea una imagen muy particular de sí misma como una noble de provincias, aunque bien conectada con el ámbito cortesano y en

${ }^{1}$ Gracias al bibliógrafo Manuel Serrano y Sanz, la vida y algo de la obra de Guevara se puso a disposición de la crítica. Sin embargo, y a excepción de las aportaciones de Serrano y Sanz (1903), Caro Baroja (1981) y Barbeito (1986 y 1992), la vida de Guevara y sus escritos no han recibido el suficiente reconocimiento hasta los últimos años, en parte gracias a la edición bilingüe de Romero-Díaz (2007). Además de la introducción de Romero-Díaz a la edición de sus textos (2007), véanse los trabajos de Langle de Paz (2003); Baranda (2005 y 2014); López Cordón (2007); Hernández (2011); Atienza Hernández (2012); Robles (2012) y la misma Romero-Díaz (2009, 2017 y 2018). Además, remito a la base de datos de BIESES (Biblioteca de escritoras españolas) en línea. continua lucha por mantener y aumentar su casa y linaje en una España en crisis. Heredera de una veintena de títulos, entre ellos el condado de Escalante por el que se la conoce, Guevara sabe manejar exitosamente su capital político y sociocultural y abrirse un hueco protagónico en la España de la época. ${ }^{2}$ Sin embargo, atrapada por este mismo linaje que parece extinguirse a falta de un heredero varón, Guevara es consciente de la importancia de intervenir públicamente como cabeza de su casa para conservar y ampliar la posición político-social que le corresponde a ella y a su familia, al tiempo de dejar una impronta histórica y personal.

Además de sus dos obras de corte político más conocidas, Tratado y advertenzias hechas por una muger celossa del vien de su rey y corrida de parte de España (1663) y Desengaños de la corte y mugeres valerosas (1664), otros textos de índole legal (e.g. litigios y testamentos) y personal (e.g. memoriales y cartas) están saliendo a la luz en diferentes archivos de la península (e.g. Archivo Histórico Nacional). En particular, y como objeto de este trabajo, me quiero detener en una documentación que pude localizar en el Archivo Histórico de Protocolos de Madrid: se trata del testamento, codicilo y memoria pre-mortem de la condesa. ${ }^{3}$ El estudio de esta documentación nos ayudará a ampliar nuestro conocimiento sobre María de Guevara, puesto que como otras mujeres nobles de la época, a través de su testamento intenta crear una imagen de sí misma y de cómo quiere ser recordada $\mathrm{y}$, con esta imagen, trata de posicionarse históricamente. En efecto, Guevara da fe de su agencia política con su testamento en la manera en que habla de sus posesiones y dispone de ellas, comenta su propia vida, reparte sus bienes y, como muchas otras mujeres en sus testamentos, "exercise[s] [her] authority over events that would necessarily happen after [her] death" (James, 2015: 1). Ahora bien, dadas las

${ }^{2}$ Por el Memorial de su casa de 1654 (también publicado en 1656), se sabe que las ramas nobiliarias de Guevara enlazan con el mismo don Pelayo, por el lado de los Ceballos, y con los fundadores del Reino de Navarra, por el lado de los Guevara.

${ }^{3}$ Debo agradecer a Teresa Díez de los Ríos San Juan, directora del Archivo Histórico de Protocolos de Madrid [AHPM], la ayuda prestada en la localización de los fondos relacionados con María de Guevara.

UNED. REI, 8 (2020), pp. 9-39

ISSN 2340-9029 
características genéricas de los testamentos, con sus formulismos legales, sus topoi retóricos y el filtro de la pluma notarial, ¿qué puede añadir esta documentación testamentaria a la imagen de la condesa que no tengamos formada gracias a sus textos políticos? ¿de qué manera particular sus últimas voluntades nos hablan de la vida de la condesa, su proyección político-social y esa impronta personal a la que nos referíamos? ${ }^{4}$

Tal y como han demostrado en los últimos años los trabajos, por ejemplo, de J. S. W. Helt (2000) o Susan James (2015) para Inglaterra, Giovanna Benadusi (2004) en Italia y María Isabel Martínez Mira (2011 $a$ y $b$ ) o Anastasio Rojo (s.a.) en el caso de España, los testamentos femeninos vienen suscitando un gran interés histórico entre los investigadores, ya que se presentan no solo como valiosos registros legales de una época, sino sobre todo por ser significativos productos culturales que "custodian" la memoria de las mujeres tras su muerte, por una parte dando continuidad a una imagen social que quieren proyectar de sí mismas desde el pasado hacia el futuro y por otra, creando lo que se podría considerar "the most 'public' perception of themselves" (Martínez Mira, $2011 b$ : 106). ${ }^{5}$ Es cierto que el estudio de los testamentos nobiliarios nos permite entender mejor cada clase social por lo que es, por cómo se percibe y por cómo quiere ser percibida. ${ }^{6}$ Para la aristocracia, tanto mujeres como hombres muestran en sus testamentos "el mismo deseo de prolongar más allá de la vida un estatus social de privilegio y contribuir de esa forma al reconocimiento identitario de su linaje y a la construcción de un ideal y modelo de nobleza al que ambos, señor y señora, contri-

${ }^{4}$ Preguntas similares se formulan alrededor de la figura de Leonor López de Córdoba en el análisis de su testamento por Lacarra (2009). Salvando la distancia temporal y las diferencias entre ambos testamentos (mucho más detallado el de Guevara), es significativo observar cómo ambas utilizan este tipo de documento para posicionarse social y políticamente teniendo en cuenta su linaje, su patrimonio y sus relaciones personales.

${ }^{5}$ Helt enfatiza el valor custodial de los testamentos con respecto a la memoria de la persona que testa (2000: 189).

${ }^{6}$ Martínez Mira cita a Bourdieu al hablar de la distinción que define a la nobleza en cuanto a que "a class is defined as much by its perceived being as by its being" (apud Martínez Mira, 2011b: 103). Sobre los testamentos en la edad moderna en general, quiero destacar el trabajo de Esteves Santamaría (2017), básico para este ensayo. buyen" (Guerrero Navarrete, 2016: 110). Las nobles, en este sentido, son conscientes de su estatus social y expresan en sus testamentos un reconocimiento a su doble linaje, el de su padre y el de su marido, haciendo pública su posición en una jerarquía vertical (Guerrero Navarrete, 2016: 97). Pero los testamentos de las nobles, además de marcar esta verticalidad, también hacen hincapié en sus relaciones horizontales, es decir, sus redes clientelares, sus alianzas y sus comunidades, principalmente femeninas, con las cuales viven y socializan diariamente, esa "casa" de las damas "a las que la señora 'cría' y 'casa'; y a cuyo cargo queda el cuidado físico y espiritual de su persona, así como la ayuda y asesoramiento en tareas de gestión y de gobierno" (Guerrero Navarrete, 2016: 105). Como afirman Helt (2000: 199) y Benadusi (2004: 811), entre otros, mientras que los hombres se preocupan más por establecer una descendencia de sus bienes de forma lineal, las mujeres también establecen otra en su horizontalidad y distribuyen sus posesiones dentro de los círculos sociales que las rodean (amistades, personal de servicio, vecinos/as, etc.). Pero no solo eso, las mujeres nobles en sus testamentos también incorporan en sus disposiciones más detalles que los hombres y personalizan la narrativa de cada una de ellas, haciendo una distribución de sus intereses de forma que llega a ser mucho más que un listado de órdenes y peticiones, ya que se expresan "more freely than at any point in their lives" (Helt, 2000: 167) y dichas disposiciones se caracterizan por su emotiva discursividad. De esta manera, los testamentos para las mujeres no son simplemente documentos legales de orden administrativo, sino "an archive of emotions, a medium for communication, commemoration and engagement" con el que memoralizan a la persona que los dispone para la posteridad (Helt, 2000: 167). Hacer un análisis de los testamentos de mujeres, a fin de cuentas, viene a ser sumamente útil a la hora de reconstruir cómo estas se posicionaban y deseaban proyectarse socialmente, para así entender mejor cómo se veían y cómo querían ser vistas y recordadas por la sociedad en general.

En este sentido, con la documentación testamentaria entre manos podremos comprender mejor la forma en que María de Guevara estructuraba su vida en términos políticos y socioeconómicos, sus valores mo- 
rales y religiosos, sus costumbres, sus vínculos familiares y, más importante, sus relaciones afectivas y sociales. El testamento de Guevara (con su codicilo y su memoria), como el de otras muchas mujeres, se convierte entonces, por su papel custodio, en una memoria de su vida en la que se establece claramente el rol de los protagonistas de dicha memoria y se hace una clara distinción identitaria entre el yo que se auto-representa y aquellos que, siguiendo sus mandas y disposiciones, la recordarán tras su muerte. Con el análisis del testamento de Guevara, en suma, no solo conoceremos mejor cómo se percibía Guevara a sí misma en el entramado social del que formaba parte, sino que además mostraremos cómo quería que la percibieran los demás y cómo quería que perviviera dicha percepción tras su muerte. Como explica James con respecto al caso inglés, pero fácilmente trasladable al español, mujeres como Guevara "were not shy about using the power of the will to authorize their last commands [and] where they could not authorize, they sought to influence" (2015: 2). El testamento se alza, junto con sus escritos de corte político, como un espacio escritural de expresión ideológica para una noble con sólida consciencia social y de género sexual, la cual, al ocaso de su vida, viuda y sin descendencia, busca con determinación dejar una huella personal e histórica tras su muerte.

Los documentos que componen las últimas voluntades de la condesa son tres, incluidas las certificaciones de notarios y testigos relacionados con la composición y apertura de los mismos, los cuales entran en juego tras su defunción en Madrid el 3 de febrero de 1683. En primer lugar, nos encontramos con el testamento cerrado otorgado por María de Guevara, condesa de Escalante, en Valladolid, el 3 de diciembre de 1678, ante el escribano Pedro de Paz Docazal y protocolizado en Madrid ante el escribano Manuel Martínez Uriarte el 17 de febrero de 1683 - a los 14 días de su defunción-; en segundo lugar, tenemos el codicilo otorgado por María Ladrón de Guevara, Condesa de Escalante, en Madrid, con fecha del 6 de diciembre de 1681, ante el escribano Isidro González; por último, existe una memoria testamentaria pre-mortem otorgada en Madrid el 8 de enero de 1683 (apenas una semanas antes de su defunción), protocolizada igualmente el 17 de febrero de 1683 ante el escribano Manuel
Martínez Uriarte. ${ }^{7}$ Los tres documentos contienen la firma de la condesa al final de cada uno de ellos, junto a la de los escribanos, los albaceas y los testigos. A pesar de los apenas cuatro años que separan la composición del testamento en 1678 y la memoria redactada a pocos días de su muerte, se pueden observar ciertas diferencias, además de las propias del género escritural que rige cada uno de los documentos, las cuales resultan relevantes, ya que revelan los entresijos familiares y afectivos de Guevara, afectados por reconciliaciones, enfados o defunciones, y que obligan a la condesa a hacer ciertos ajustes en sus mandas y disposiciones.

Estructuralmente, el documento principal de 1678 no varía mucho de los testamentos nobiliarios de la época. ${ }^{8}$ Este se abre con un preámbulo o encabezamiento donde se presenta la testamentaria, con la enumeración de todos sus títulos (intitulación del testador), seguido de las declaraciones religiosas (protestación de la fe). Como hizo en el memorial de 1654, en que reivindicaba al rey ciertos títulos y derechos económicos perdidos, Guevara lista los títulos que la posicionan nobiliariamente y de los que se enorgullece, dado el mucho trabajo y el esfuerzo personal que ha puesto en conservarlos y mejorarlos durante su vida: “yo, Doña Maria de Guebara Manrique de abendaño y beamonte Condesa de Escalante y de tahalu, Marquesa de Rucandio señora del Valle de Baldalega, y de las casas de çeballos, y abendaño, olaso, Urquizo, Arazuri montalban y de las Villas de Villareal de Alava y osornillo" (f. 77r). ${ }^{9}$ Tras el listado de títulos, la condesa indica que está viuda de "Don Luis Andres Velazquez de belasco conde de escalante que fue" e informa de su estado de salud mental (juicio y entendimiento), como es habitual en este tipo de documentos (f. 77r). A continuación, hace las debidas invocacio-

${ }^{7}$ Todos los documentos se encuentran en el Archivo Histórico de Protocolos de Madrid (AHPM). El testamento y la memoria están juntos bajo la signatura T.12449, f. 67r-96v y el codicilo, T.12352, f. 761r-762v.

${ }^{8}$ Sobre los testamentos de la Edad Moderna en general, existe una bibliografía abundante. Remito por ejemplo los trabajos de Martínez Gil (1993); García Fernández (1996); Vilar y Kuethe (2006); Valdés Pozueco (2010); Mártir Alario (2011); Tabernero (2016); o Esteves Santamaría (2017).

${ }^{9}$ Las citas del testamento, codicilo y memoria son textuales y he mantenido la ortografía original.

UNED. REI, 8 (2020), pp. 9-39

ISSN 2340-9029 
nes religiosas como creyente y se encomienda a la Santísima Trinidad, la Virgen, la Santa Iglesia Católica y los Santos Padres - también habitual en toda protestación de fe-. Así se cierra el protocolo inicial.

El cuerpo del testamento se abre con la declaración de las cláusulas dispositivas relacionadas con sus exequias y sigue con la exposición de sus mandas tanto forzosas (donaciones, limosnas, liberación de esclavos, etc.), como voluntarias (repartición de bienes, propiedades y otras pertenencias), en las que se detiene, como se verá, de una manera muy personal y minuciosa. El testamento se cierra con la reiterada insistencia en que esta es su última voluntad, las firmas de albaceas y las de los testigos que dan veracidad y legitimidad a la apertura del documento. A pesar de la riqueza de este documento, la condesa explica en varias ocasiones que el testamento viene acompañado de

un libro [donde] tengo espresados todos los vienes muebles de mi casa que consisten en Ropa blanca, tapices, bufetes y cofres y demas menajes de casa y asi bien en una memoria que se allara en la cartera que esta en el escritorio de letra la dicha memoria de Agustín de Montiano y firmada de mi mano en la qual se espresa la plata labrada y dinero que ay al presente en mi poder $\mathrm{y}$ asi al asiento del libro referido como a la dicha memoria se de toda fee y credito y sirva de discrepcion y Imbentario de Vienes que asi es mi voluntad (f. $87 \mathrm{r}-87 \mathrm{v}$ ).

Desafortunadamente, ni el libro ni la memoria a los que se refiere han sido localizados por el momento, aunque la memoria pre-mortem de 1683, a pocos días de su muerte, hace alusión a la distribución del menaje del hogar y otros objetos personales, común a este tipo de documento. En cualquier caso, resulta significativo que en ninguna ocasión la condesa haga referencia a su biblioteca — si bien esta información podría haberse incluido en ese "libro" o la tal "memoria" aún desaparecidos—, ni a sus propios escritos, por lo que aún solo es posible acercarnos a su capital intelectual a través de las referencias que surgen de la lectura detenida de sus textos, tal y como así lo han hecho Baranda (2005) y Romero-Díaz (2007)..$^{10}$

De las cláusulas religiosas destacan el énfasis y detalle que Guevara pone en la selección de su enterramiento. ${ }^{11}$ De hecho, son tres los posibles lugares que propone:

a. Valladolid, donde la condesa se halla en el momento de composición del testamento de 1678 "esperando a que se vote un pleito", 12 más específicamnte en el convento de Santa Cruz en Valladolid, "en el gueco que esta devajo del Altar mayor de dicha Iglesia donde estan sepultadas mis primas" (f. $77 \mathrm{v})$.

b. Madrid, donde reside habitualmente en esa época, "en la bobeda primera del conbento de nuestra señora de atocha del horden de Santo Domingo de que es patron el conde de nieva mi sobrino y donde sean enterrados los dichos condes de nieva" (f. $77 \mathrm{v}){ }^{13}$

${ }^{10}$ En un reciente artículo de Anne J. Cruz (2019) se habla de la diferencia entre las escritoras de la edad moderna conforme a su clase social. Son las aristócratas las menos "artísticas" en cuanto a los géneros que tocan (la mayoría no de ficción, como son las cartas o los tratados político-didácticos). Como explica Cruz, cuando escribían, las aristócratas "served primarily to promote their own interests as political players within the social system" y con respecto a las obras de ficción, eran las principales consumidoras y mecenas, por lo tanto, no había necesidad de crear un yo autorial-literario que las autorizara en el espacio público (358). Para Guevara, sus escritos políticos han cumplido una función política primordial, igual que lo han hecho sus memoriales y lo hará su testamento al final de su vida.

${ }^{11}$ Francisco R. Uhagón (1901), con motivo de estudiar el Santo Cristo de María Estuardo reina de Escocia, hace referencia al testamento y codicilo de la condesa y da detalles sobre la vida de la misma, incluidos sus maridos. Este Santo Cristo, como explica el testamento de 1678, era un regalo de la reina Isabel de Borbón y, tras la muerte de la condesa, fue donado al convento de Santa Cruz en Valladolid por manda testamentaria (f. 85r).

${ }^{12}$ En 1678 se encuentra en Valladolid "esperando que se vote un pleito a que vine y luego me volvere a esa corte queriendo Dios," así le dice a la Duquesa de Béjar, Teresa Sarmiento de Silva, en una carta del 23 de marzo de 1678 en la que le da la enhorabuena por el parto de su hija (Archivo Histórico Nacional Sección Nobleza [AHNSN]: Osuna CT. 535, D. 5).

${ }^{13}$ Se refiere a don Lorenzo de Cárdenas, VIII Marqués de la Mota y XII Conde de Nieva, esposo de la hija de su hermana Luisa, Francisca de Saavedra, ya difunta al momento de 
c. Palencia, ya que en el momento de la composición del testamento, la condesa está a punto de salir de Valladolid a "mi billa de osornillo" para hacer unas "diligencias", de manera que si muere allí o en el camino, pide ser trasladada al convento franciscano de Palencia y ser enterrada en su bóveda donde está "la señora Doña Isabel de Mendoça condesa que fue de grajal mi prima" (f. $77 \mathrm{v}) .{ }^{14}$

Como se puede observar, la condesa no solo se limita a decidir el lugar de enterramiento, sino que, como en otros testamentos de la época, solicita "la sepultura en algún lugar concreto dentro del mismo, en otras palabras, no todo el suelo sagrado tenía el mismo valor de cara a garantizar una pronta salvación del alma" (Esteves Santamaría, 2017: 49). ${ }^{15} \mathrm{El}$ lugar que ocupa el cuerpo de la condesa a su muerte es tan importante como el que ha ocupado durante su vida, puesto que dicho lugar influirá en la manera como la sociedad la memorializará después de la muerte. $\mathrm{Al}$ situarse bajo el altar o en la bóveda primera, como detalla en cada una de sus selecciones, Guevara se asegura un lugar protagónico junto al mismo cuerpo y sangre de Cristo, expuesto en el altar mayor a todas horas y donde se consagra durante las misas.

En el codicilo de 1681, ya de vuelta en Madrid tras resolver sus asuntos legales, la condesa hace un cambio testamental y dispone que, de enterrarse en Madrid, no sea en Nuestra Señora de Atocha, sino en un cuarto y diferente lugar, el Convento de San Jerónimo, "en la capilla de los guevaras" donde, explica el escribano, está enterrada su madre y su primo don Antonio, hijo del Conde de escalante (f. 761v). Cabe notar que en el codicilo se han revocado todas las mandas que habían sido ordenadas a favor de su hermana Luisa (quizá difunta para 1681), sus

la composición de este testamento y que parece que está enterrada en dicha bóveda de Nuestra Señora de Atocha.

${ }^{14}$ La villa de Osornillo, la cual dice en su memorial de 1654 que es "la casa más antigua del mayorazgo de Escalante" (2007: 114) es protagonista de pleitos y otros asuntos de herencia a raiz de la muerte de su sobrina Francisca, a quien la había donado, con sus alcabalas, con motivo de su casamiento en 1671 (AHNSN: Fernán Núñez C. 84, D. 10).

${ }^{15}$ En relación al testamento de Leonor López de Córdoba explica Lacarra que es habitual para las mujeres dar "indicaciones muy exactas acerca de junto a quien desean ser enterradas" (2009: 200).

UNED. REI, 8 (2020), pp. 9-39

ISSN 2340-9029 hijas y sus nietas, entre las que se encuentran las hijas de su ya fallecida sobrina Francisca y el Conde de Nieva, con quien se encuentra en pleitos por la herencia de la villa de Osornillo durante estos años. ${ }^{16}$ Efectivamente, con fecha posterior a la defunción de la condesa en 1683, el viudo de Francisca ha estado reclamando la villa de Osornillo y sus alcabalas para sus hijas y herederas, Mariana de Cárdenas y María Luisa de Cárdenas, a pesar de que la condesa en su testamento ha dejado expresamente dispuesto que la villa sea desempeñada y devuelta para integrarse en el mayorazgo de Escalante (f. 86).${ }^{17}$ No es de extrañar, por tanto, que para 1681, por desavenencias con el marido de su difunta sobrina (Conde de Nieva), Guevara ya no se quisiera enterrar en la bóveda de dichos condes en Nuestra Señora de Atocha. Sin embargo, en el libro de enterramientos del Arzobispado de Madrid, queda constancia de que María de Guevara y Mendoza, Condesa de Escalante, finalmente acaba enterrada el 3 de febrero de 1683 en la iglesia de Nuestra Señora de Atocha, ¿fue esta la última voluntad de la condesa, quizá hecha en el lecho de muerte y en contra de las disposiciones testamentarias anteriores? ${ }^{18}$ Eso no lo sabremos. Lo que sí se puede concluir del análisis de las disposiciones sobre su enterramiento es que Guevara es una mujer que piensa reflexivamente y es concienzuda no solo con respecto al lugar que va a ser su casa para

${ }^{16}$ La única hija superviviente de su sobrina María de Saavedra y Guevara, Juana Luisa de Sequeiros y Saavedra, será quien reciba una dote, pero solo en caso de entrar en el convento de nuestra señora de Belén en Valladolid, ya que si falleciera antes o si no profesara, la condesa explicita que el dinero no debe ir a su madre (Codicilo f. 762v)

17 Véase el documento del pleito en AHNSN: Fernán Núñez C. 84 D. 10.

18 "La señora doña María Ladrón de Guevara, Condessa de Escalante, viuda del señor don Andrés Velázquez i Velasco, Conde de Escalante, murio en tres de febrero anño de Mil seicientos ochenta I tres, en la calle de los Embajadores, cassas de Diego Castellanos rezivio los sanctos sacramentos, tenía otorgado testamento zerrado en la Ziudad de Valladolid [3-XII-1678] ante Pedro de Paz Docazal, escribano real, el qual dicho testamento, con un cobdicilio que dicho señor tenía otorgado en esta Villa [6-XII-1681] ante Ysidro González, escriuano real, los quales dicho testamento y cobdicilio se pressentaron al señor don Phelipe Antonio de la Cueba, Alcalde de Cassa y Corte de Su Magestad [. . . ]; mandósse enterrar en el Combento de Nuestra Señora de Atocha, extramuros de esta Villa y fue de secreto con licencia del señor vicario; i dio a la fabrica de esta Iglesia de San Justo i Pastor ciento treinta i dos reales" [223-223v] en el Archivo Histórico Diocesano de Madrid [AHDM]: Caja 121, Libro 11 (Abril 1677- Mayo 1683).

UNED. REI, 8 (2020), pp. 9-39

ISSN 2340-9029 
la posteridad, sino también con respecto a quien va a acompañarla en la vida eterna, ya que para cada enterramiento, Guevara elige una compañera de viaje femenina, ya sean sus primas, su sobrina o su propia madre, y en ningún caso menciona a ninguno de sus tres maridos (de los que hablaremos más adelante), ni a su padre, ni a su tío del que heredó el condado de Escalante. Estas conexiones femeninas que la condesa establece a la hora de decidir las compañeras de esta, su última estancia, no son sino un ejemplo de la consideración que la condesa pone en las relaciones femeninas tanto en vida como a la hora de la muerte y a las cuales, como se verá, memorializará en sus últimas voluntades.

Junto a la decisión de la testadora sobre el lugar de enterramiento, es también importante en los testamentos disponer las celebraciones litúrgicas que se deben llevar a cabo por su alma y, en algunos casos, la de sus más allegados, ya que de su celebración dependerá la duración de su paso por el purgatorio y el que su nombre y su persona se sigan rememorando durante los años venideros para mantener viva su memoria. Como en otros testamentos de la época, Guevara deja constancia de las misas que se deben realizar a la mayor brevedad en el lugar donde muera (ocho mil misas a 2 reales de vellón por cada una), además de las que corresponden a su parroquia (seis mil) y las que se deben celebrar en los conventos de su devoción o de los que ella es patrona (f. 78r) - a estas hay que añadir las que debían decirse por sus padres (400 misas) (f. 78v) —. ${ }^{19}$ Para mostrar su santidad, piedad $y$, sobre todo, caridad como noble modélica, Guevara también exige que el día de su entierro se vista a doce pobres y se reparta dinero entre los pobres y viudas que se encuentren a la puerta de su casa, que se dedique una cantidad al rescate de cautivos en los Mercedarios de la ciudad en la que muriese y que se pague a sus criados y criadas todo lo que se les debe hasta que se acomoden con otra familia o regresen a sus pueblos o villas (f. $78 \mathrm{v}-79 \mathrm{r}$ ). Como noble comprometida con sus títulos, con su familia y el lugar social que ocupa

${ }^{19} \mathrm{Al}$ final de su testamento de 1678, ordena que, una vez cumplidas sus mandas, se funde una capellanía con tres misas por semana, por ella, sus padres y sus maridos en el convento de Santa Cruz en Valladolid si fuera enterrada ahí (f. 88r-89r). Es esta la única atención con sus maridos en todo el testamento. y por el que se preocupa a lo largo de su vida, Guevara debe actuar en consecuencia.

Las claúsulas que siguen a las disposiciones espirituales hasta el final de su testamento de 1678 , así como a las decisiones y cambios que se exponen en el codicilo de 1681 y en la memoria de 1683, corresponden a las disposiciones materiales (bienes monetarios e inmuebles, propiedades, bienes personales, etc.) que a falta de herederos forzosos (viuda y sin hijos), debía mantener dentro del patrimonio familiar y para el caso de mujeres testadoras como ella, repartir entre los criados y personal de servicio (2007: 86).$^{20}$ En vida, Guevara ha sido una mujer implicada directamente en el mantenimiento, ampliación y mejora de sus tierras y propiedades, ya que, como ella misma predica en sus escritos políticos, estas tierras y propiedades han sido visitadas, habitadas y protegidas por ella en persona como propietaria. No se trata de propiedades reducidas discursivamente a un listado de títulos, sino que para Guevara son espacios vivos, que se han humanizado con la presencia de su propietaria y que, como vemos por su testamento, se han transformado (creciendo y mejorando) gracias a la cuidadosa intervención (y las numerosas inversiones económicas) de la misma. Efectivamente, al heredar la mayoría de sus títulos nobiliarios tras la muerte de su tío el conde de Escalante (1643), la nueva condesa de Escalante, María de Guevara, se establece en una posición de autoridad en cuanto a la protección, mantenimiento y aumento de sus propiedades. ${ }^{21}$

Ninguno de sus tres maridos parece que se haya hecho cargo apenas de sus propiedades, unos por pronta defunción, otros simplemente por desinterés. A su primer marido, don García Bravo Osorio, no lo nombra en su testamento, aunque sí lo hace en su Memorial de 1654 donde dice que es "Marques del Villar señor del mayorazgo de Ocaña

\footnotetext{
${ }^{20}$ Para el Tratado y los Desengaños de Guevara cito por la edición de Romero-Díaz (2007) ${ }^{21}$ El título de Condesa de Escalante lo hereda a la muerte de su tío, don Luis Ladrón de Guevara, el 23 de marzo de 1643 ("Testamento del Conde de Escalante," en AHNSN: Fernán Núñez C. 865 D. 9), ya que la única heredera de este y prima de la nueva condesa, Ana Catalina de Guevara, se había muerto sin sucesión en 1641, tal y como consta en los Avisos de Pellicer con fecha del 29 de enero de 1641 (Valladares, 1790: 274-275).
}

UNED. REI, 8 (2020), pp. 9-39

ISSN 2340-9029 
que fundò Pero Alvarez de Osorio, hijo segundo del Marques de Astorga" (f. 19r) y es con quien posiblemente se traslada de su natal Jerez de los Caballeros a Valladolid. ${ }^{22}$ Para 1643, fecha del testamento de su tío, ya está casada en segundas nupcias con don Lorenzo Ladrón de Guevara, deudo suyo, "escudero de su casa" y señor de Paradilla y Alcor de Campos. Don Lorenzo es segundón de una rama de los Ladrón de Guevara bien asentada en Valladolid y entregada al ejercicio militar, como queda demostrado en los expedientes militares de su padre don Carlos y su hermano don Pedro, ambos capitanes de Felipe II..$^{23}$ Su matrimonio debió ser breve, puesto que en el testamento de 1644, don Lorenzo habla de su enfermedad y para 1645 ya existe una solicitud de la condesa al Consejo de Castilla pidiendo permiso para casarse con un madrileño, don Andrés Velázquez de Velasco, su tercer y último marido, fallecido antes de 1678 cuando la condesa dice estar viuda. ${ }^{24}$ Este tercer matrimonio no debió ser muy feliz y la ausencia del marido en vida fue la nota común de su convivencia. Efectivamente, se sabe que don Andrés Velázquez de Velas-

${ }^{22}$ El testamento de su tío don Luis de Guevara menciona este matrimonio, aunque por los únicos datos recabados, un tal don García Bravo Osorio, con los mismos títulos referidos por la condesa, solo estuvo casado con Mariana Ortiz de Atienzo con quien tuvo sucesión (Catalina Bravo Osorio) y de quien enviudó en1635 (según consta en el testamento de la abuela de la joven y madre de la tal Mariana con fecha de junio de 1635) ("Testamento e inventario").

${ }^{23}$ Antes de casarse con la condesa, don Lorenzo ya había estado casado con doña Mariana del Castillo y Sotomayor, según consta en las capitulaciones otorgadas el 5 de abril de 1630 y había enviudado en 1636, poco después de que hiciera testamento la tal doña Mariana (Archivo General de Simancas [AGS]: Contaduría de Mercedes [CME] 33, Leg. 13). Don Lorenzo Ladrón de Guevara había sido nombrado corregidor de Medina de Campo en 1636 (AHN, Consejos: Leg. 13617, Exp. 17). Hay constancia de un pleito de 1671 entre María de Guevara y don Diego del Castillo en relación a la herencia de don Lorenzo; en dicho documento se menciona que este fue su primer marido (AGS: CME

33, Leg. 13, f. 907r), lo cual contradice los datos que la misma condesa deja escritos en su Memorial de 1654.

${ }^{24}$ En el testamento de don Lorenzo, con fecha de 29 de julio de 1644, se indica que este está enfermo y que deja todo a su esposa, la condesa, quien lo ha acompañado y cuidado durante su matrimonio. Este testamento se encuentra entre los legajos asociados al pleito con don Diego del Castillo (AGS, CME 33, Leg. 33, f. 907v y ss). La petición de Guevara para casarse con don Luis tiene fecha del 20 de diciembre de 1645 (AHN Consejos: 13201, A.1645, Exp.134). co pasó la mayor parte de su vida lejos de la condesa, bien cumpliendo con su labor militar, bien gastando "su dote" en diversiones cortesanas y en cualquier caso, abandonando su labor como cabeza masculina de la casa de Escalante. ${ }^{25}$ Por el contrario, Guevara demuestra continuamente que no necesita de ningún marido para llevar a cabo su tarea de administración y mejora de su patrimonio. La imagen pública en vida de mujer independiente, esa mujer "que vale más que dos hombres", como dicen sus criadas en 1659 (Guevara, 2007: 121), se corresponde así con la que construye y proyecta en su testamento, en el cual insiste en su labor individual y en una conexión personal con sus propiedades.

El cuerpo central de su testamento precisamente hace un recorrido espacial por todos sus estados, no solo en sentido memorial, sino presencial, ilustrando en cada alusión la importancia personal y su significado político, social y económico. Cada una de las propiedades asociadas con los títulos heredados es reconstruida literalmente por la condesa en el testamento, haciéndolas habitables y/o productivas, liberadas de deudas o recuperadas de pleitos, siempre aumentadas y mejoradas. En este sentido, Guevara no acumula títulos, sino que los vive, ampliándolos y protegiéndolos. El testamento se hace eco de la incansable labor de Guevara por restaurar la posición de su familia, antes en ruinas (literales y simbólicas), y darle una continuidad, una proyección hacia el futuro. ${ }^{26} \mathrm{~A}$ falta de sucesión biológica, sus títulos y propiedades se convierten

${ }^{25}$ Como soldado, don Andrés había acudido a los frentes de Burdeos (1654), Évora (1661) donde es hecho prisionero, Entremoz-Ameixial (1663) y Badajoz (1664), entre otros. En el Diccionario biográfico matritense se dice que estaba casado "con doña María de Guevara, Condesa de Escalante y de Tahalú, señora de mucho ingenio, que en 1656 escribió é imprimió un Memorial de su casa, que gobernaba con sumo acierto, en ausencia de su marido" (Ballesteros, 1912: 663). La ausencia de don Luis ya la había criticado la condesa en 1653 cuando escribió al Conde de Haro quejándose por el abandono de su marido, quien después de jugarse su dote y "sin su consentimiento [ni] beneplacito" se ha ido a la corte, donde intenta unirse de nuevo al servicio de su Majestad y donde "no esconde la decencia y autoridad que debe hacer a ejemplo de mis progenitores" ("Carta de doña María de Guevara II," RAH: Colección Salazar y Castro, 54659 M-69, f. 97).

${ }^{26}$ Ya lo advertía su tío abuelo fray Antonio de Guevara un siglo antes en una de sus epístolas al referirse a los siete mayorazgos de los Guevara, los cuales "todos son valerosos en sus personas aunque pobres en estados y rentas; de manera que los de este linage 
en su mejor descendencia. Así, en el testamento de 1678, tras disponer como inmediata sucesora del estado de Escalante y Avendaño y sus mayorazgos a su hermana Luisa de Guevara, viuda del señor don Martín de Saavedra y Guzmán, Guevara incorpora una primera manda sobre su patrimonio (número 18) en la que explica y declara "que yo he hecho muchas mejoras en los mayorazgos que poseo" (f. 80v-81r). ${ }^{27}$ Por ejemplo, y siguiendo lo establecido en el testamento de su segundo marido don Lorenzo, Guevara no solo ha nombrado dos capellanías para la iglesia de la Consolación de Escalante, las cuales deben ser cuidadas, aderezadas y reparadas por sus sucesores, sino que además, tras heredarlas de dicho marido, "hice algunas mejoras en el dicho estado y mayorazgo como son el aderezo del Palacio de Osornillo, que estava caido ... y gaste cinco mill seicientos y treinta y quatro rreales" (f. 81v). Además, arregló el palacio de Treceño primero e incluso lo hizo de nuevo (f. 82r), al igual que "todos los demas molinos y herrerrias que tengo en todas partes los he aderezado muchas veces en que he gastado muchos ducados" (f. 82r), y en Elgoibar se levantó un pleito por unos manzanares, pero los luchó y ganó "y gaste mucho" (f. 82r), y en 1659 "fui a la dicha villa de Villareal para acavar de enladrillar los suelos de dicho palacio", gastando 1.227 reales (f. 83r-83v), y muchos palacios que tenía en diferentes propiedades y que estaban caídos, los intentó arreglar aunque a veces no tuvo tiempo ni dinero suficiente para aderezarlos (f. 83r), y encima de todo, pleiteó contra el consejo de cámara del rey (f. 83r), el Nuncio (f. 83r-83v), y los vecinos de Ararzuri (f. $84 \mathrm{v}$ ) y otros muchos por los juros, molinos, plantas, etc. que le correspondían y, dice la condesa, siempre ganó. El testamento, a manera de cartografía vital, realiza un detallado recorrido por las propiedades que la condesa ha navegado en vida, como buena señora de su casa, y en cada una de ellas, su intervención es descrita con todo detalle (incluso dando fechas y especificando los gastos), posicionándose para la posteridad a través de la construcción (la más importante de su vida) de

de Guevara más se prescian de la antigüedad de do descienden que no de la hacienda que tienen", "Letra para don Íñigo de Velasco, 8 de Octubre 1525" (Guevara, 2000).

${ }^{27}$ Entre estos mayorazgos que posee, también se incluye el heredado de su madre, Francisca de Mendoza, de Jerez de los Caballeros en Extremadura, lugar que vio nacer a la condesa, y por cuyo valor lucha fervientemente en el Memorial de 1654. un registro escrito de su historia patrimonial. Al fin y al cabo, Guevara no hace sino actuar como una modélica cabeza de familia, algo que alababa en sus escritos políticos y por lo que desafíaba a su rey y a todos los nobles (inclusive su marido), quienes, en su opinión, habían fallado en su función. Con la construcción y reconstrucción material de sus propiedades, Guevara no hace sino erigir una memoria sobre ella misma para la historia y el testamento se convierte en el custodio de dicha memoria.

Ahora bien, Guevara no está sola en sus viajes por sus propiedades durante su vida, como tampoco lo está en ese último viaje que hace después de la muerte. El testamento es un claro testimonio de las redes familiares y sociales así como de los vínculos afectivos que se han ido formando a lo largo de los años. Cabe destacar que, con ciertas excepciones, el grueso de los herederos y legatarios de sus mandas voluntarias está dominado por mujeres con quienes le unen lazos de consanguinidad así como lazos de amistad y/o servicio. Junto a los nombres que reciben la atención de Guevara en su testamento se genera además toda una narrativa que nos ayuda a reconstruir la calidad de dichos lazos y, de alguna manera, nos ayuda a vislumbrar, como hemos venido diciendo, cómo era María de Guevara y la imagen que proyectaba o quería proyectar de sí misma en relación con los demás tras su muerte. La condesa cumple así con lo que ya era habitual en los testamentos femeninos de la época, en los que, a diferencia de los testamentos de hombres, las mujeres "spent more time than their male relatives distributing gifts and dictating itemized lists"-listados que eran acompañados de aclaraciones y explicaciones personales a sus decisiones-(Benadusi, 2004: 181). Es decir, en el proceso de recolección y distribución de sus bienes, con todo su componente selectivo y estructural, las nobles testadoras dan testimonio no sólo de su capital económico y cultural, sino que también ponen de manifiesto dinámicas sociales sobre sus relaciones personales al igual que dinámicas de poder e influencia en cuanto a los círculos en los que se mueven y viven. Es significativo pues analizar la manera en que estas mujeres expresan sus conexiones personales y afectivas con sus legatarias, sus preferencias con respecto al uso e inversión futuro de sus bienes y otras estrategias que afectan y condicionan el uso de sus legados. Esta 
forma de expresión distintiva de los testamentos femeninos difiere en buena medida de la proyección identitaria que buscan los hombres en documentos similares. Como decíamos, mientras que los nobles de la época se proyectaban en sus testamentos de forma vertical (haciendo especial hincapié en su descendencia biológica), las mujeres se proyectaban también de forma horizontal, "incorporating an extended family that included servants and far relatives" e implicaban "a greater awareness of social interactions and obligations than has generally been assumed" (James, 2015: 2); proyección que se traslada al testamento con un alto grado emotividad y en muchos casos, expresada "more freely than at any point in their lives" (Helt, 2000: 167). A través del testamento, las nobles de la edad moderna tratan de extender después de la muerte lo que ya hacen a lo largo de su vida, es decir, crear redes de sociabilidad y desarrollar estrategias que les permitan tener una influencia social que contribuya a proteger y enriquecer (económica y simbólicamente) sus familias al tiempo que las autoriza en una posición de poder. Por tanto, en sus testamentos, como se verá en el caso de Guevara, las mujeres hacen explícitas las redes más cercanas a su quehacer cotidiano y distribuyen sus bienes teniendo en cuenta relaciones afectivas y personales, lo cual lleva a adentrarnos en sus círculos más íntimos y observar dinámicas sociales, por ejemplo entre las señoras y sus criados y criadas, o interdependencias entre estas mujeres y los espacios que habitan (la casa, el barrio y sus propiedades).

Si bien los escritos políticos de María de Guevara nos ofrecen una visión bastante precisa de una "comunidad" femenina intelectual y política (esa galería de mujeres ilustres con la que la condesa ejemplificaba un modelo de acción y de la que ella misma se alzaba como cabeza), en el testamento nos encontramos, por el contrario, con una "comunidad" femenina real de tipo personal y afectiva. Esta comunidad sobresale aún más ante la ausencia casi absoluta, salvo excepciones, de figuras masculinas dentro del testamento. Ni siquiera aquel que finalmente hereda el estado de Escalante y Avendaño y demás mayorazgos, don Martín de Saavedra y Ladrón de Guevara, hijo de su hermana Luisa, aparece en los documentos entre manos, ni de albacea ni testigo, y ni siquiera es reconocido en sus mandas. Es el gran ausente de su testamento, al igual que sus maridos han sido los grandes ausentes de su vida. Junto a algún vecino nombrado en su memoria, los únicos hombres de los que deja constancia en su testamento son los que junto con su hermana doña Ana de Guevara (Luisa solo aparece como albacea en el testamento de 1678, pero no en el codicilo de 1681 ni en la memoria de 1683) son ejecutores del testamento. Estos son el V Marqués de Aguilafuente, don Manuel de Zúñiga Ramírez de Arellano, su primo; el padre prior del Convento de Santo Domingo en Valladolid; don Ambrosio Thomás de la Canal, canónigo de la Santa Iglesia Catedral de Palencia; don Agustín de Montiano, "agente de negocios" en la Real Chancillería de Valladolid; a los que hay que incorporar del codicilo de 1681, don Melchor de Zeballos, del consejo de su majestad; y don Agustín de Álava, procurador de la villa de Madrid. Todos ellos, en agradecimiento por su labor de curadores de su última voluntad, reciben algunas "memorias de su buena voluntad", como son una cruz de reliquias, láminas de su oratorio y escribanías de ébano y marfil (Testamento f. 88v; Codicilo f. 762). Como explica James, la entrega de regalos a los ejecutores de los testamentos sirven a la testadora para asegurarse que hagan bien su trabajo y cumplan su función (2015: 189).

Las principales protagonistas y beneficiarias de sus bienes son sus hermanas, Luisa y Ana, sus sobrinas y sus sobrinas nietas. De hecho, su hermana Ana de Guevara y familia cobran aún mayor protagonismo en el codicilo de 1681 y su última memoria de 1683 (a semanas de su muerte), probablemente debido a la muerte de su hermana Luisa y quizá a un mayor acercamiento a la misma en los últimos años de su vida, ya que por entonces la condesa residía en unas casas de la calle Embajadores cercanas a las de su hermana Ana. ${ }^{28}$ Efectivamente, Luisa de Guevara

${ }^{28}$ El Libro de enterramientos dice que "La señora doña María Ladrón de Guevara, Condessa de Escalante, viuda del señor don Andrés Velázquez i Velasco, Conde de Escalante, murio en tres de febrero anño de Mil seicientos ochenta I tres, en la calle de los Embajadores, cassas de Diego Castellanos . . . i nombró por sus testamentarios, por el dicho cobdicilio a la señora doña Anna de Gueuara, su hermana, que uiue junto [223] a dicha cassa ..." (AHDM: C. 121, L. 11, f. 223-223v). Esta, sin embargo, no es la única vivienda conocida de Guevara durante sus estancias en Madrid. Por una carta de Pedro 
desaparece del codicilo de 1681 y aunque Guevara dice revocar todo lo dispuesto en el testamento de 1678, no se menciona nada de las mandas con respecto al estado de Escalante y Avendaño y sus mayorazgos. ${ }^{29}$ En el testamento de 1678 solo salen beneficiadas sus sobrinas-nietas por parte de las dos hermanas de don Martín (María y Francisca de Saavedra) y por tanto, hijas de Luisa de Guevara: Baltasara y Juana de Sequeiros y Saavedra (hijas de María de Saavedra) por un lado, y Mariana y María Luisa de Cárdenas y Saavedra (hijas de la ya difunta entonces Francisca de Saavedra), por otro. Las condiciones impuestas en las mandas ponen de manifiesto que la generosidad familiar viene asociada con un sentido claro de posición social y de autoridad tras su muerte, ya que mientras para unas, las de Sequeiros, se trata de una dote solo y exclusivamente en caso de entrar en religión, para las de Cárdenas, entonces damas de la reina, los bienes nombrados deben servir para tomar estado y si mueren antes de hacerlo, exige que no los reciban, sino que sean devueltos para desempeñar la villa de Osornillo y añadir su valor al mayorazgo de Escalante (f. 85r86r). Ninguna de sus decisiones se llevan a cabo, ya que para 1681, muy probablemente por desavenencias personales con María de Saavedra y con Lorenzo de Cárdenas (esposo de su sobrina difunta Francisca), María de

Morana sabemos que en 1667 la Condesa de Escalante vivía en una casa que lindaba con el jardín del Palacio del Conde de Lemos, en la plazuela de Santiago, la cual parecía estar sufriendo problemas de humedad (AHNSN: Osuna C.414, D. 253).

${ }^{29}$ Como se ha mencionado, resulta significativo que su directo sucesor, don Martín de Saavedra y Ladrón de Guevara, quien finalmente heredará el Condado de Escalante, no aparezca en ninguno de los documentos testamentarios. Don Martín de Saavedra y Ladrón de Guevara, como su tía, compone varios memoriales $(1658,1665$ y 1683) dirigidos al rey en los que requiere que le conceda las mercedes, títulos o hijosdalgo que por sus servicios y los de su familia merece, principalmente por los de su padre, don Martín de Saavedra y Guzmán (1594-1654), Caballero de la Orden de Calatrava, presidente de la Audiencia de Nueva Granada de 1637 a 1645, entre otros, y también poeta. El gobierno de don Martín de Saavedra y Guzmán en las Indias, sin embargo, fue algo cuestionable, dado su comportamiento indebido, el cual le llevó a la cárcel. Las intervenciones de su esposa doña Luisa de Guevara, fundamentales en la defensa y final liberación de su esposo, están aún a la espera de una investigación. Véase a este respecto, entre otros, el capítulo de la Historia Extensa de Colombia dedicado al gobierno de don Martín en Nueva Granada (Lucena Salmoral, 1966: pp. 184-207). ¿Podrían ser estos asuntos delicados con la justicia los que provocaran un distanciamiento con su sobrino?
Guevara revoca todas sus mandas, excepto por una pequeña dote que da a su sobrina Juana solo y exclusivamente si profesa en el Convento de Nuestra Señora de Belén de Valladolid (f. 761v-762r). ${ }^{30}$

Por el lado de Ana de Guevara, la hermana pequeña de la condesa, pasa lo contrario. ${ }^{31}$ Ana es la única de su familia que es mencionada en el testamento de 1678 en el que se dispone que reciba "la madera de la cama en que duermo y la colgadura della" además de 2.000 ducados de vellón y nueve reposteros con las armas de Gamboa (f. 73r-73v). Además de nombrarla como una de sus albaceas, al entregarle la cama donde duerme le demuestra un alto grado de afecto, ya que, como explica James, la cama era "one of the most significant and valuable pieces of furniture in the house" (2015: 87). Sin embargo, a pesar de esta demostración de afecto, si Ana muriera antes que ella, la condesa dispone que sus herederos no cobren nada, excepto por unas supuestas "niñerías" que en el codicilo dice haber dejado a su sobrina Ana de Alagón, III Condesa de Fuenclara (f. 762v) ${ }^{32}$ Cualquiera que fuera la discordia con los herederos de su hermana, esta parece solucionarse en los años siguientes, puesto que para 1681 la condesa pide perdón a su sobrina Ana de Alagón y dispone para ella una alfombra para viuda con siete almohadas de damasco y once reposteros con las armas de Guevara (anteriormente destinados a su hermana Luisa) (f. 761v) y, para los hijos de esta (Bartolomé y Josefa), pide que en caso de fallecer su hermana Ana, lo hereden todo y reciban además 1.000 ducados de vellón cada uno para tomar estado y que en caso de muerte temprana, esta herencia pase a su madre, Ana de Alagón (f. 761v). Ana de Guevara, hermana, vecina y compañera de la condesa

${ }^{30}$ Juana Luisa de Sequeiros y Saavedra nunca llegó a profesar, sino que tomó estado con don Juan Antonio Patiño de Lamas y Sotomayor.

${ }^{31}$ Doña Ana de Guevara, aunque se prometió, nunca se llegó a casar con don Enrique de Alagón y Pimentel, VIII Conde de Sástago, muy a pesar de las intervenciones del mismo rey Felipe IV para que cumpliera con su palabra de matrimonio. A pesar de no casarse con doña Ana, reconoció a sus dos hijos, quienes heredaron sus títulos y posesiones (Fantoni y Benedí, 2000).

${ }^{32}$ En el testamento, la cláusula 48 dice que se dé a su sobrina la condesa de Fuenclara un escritorio pequeño de bronce y acero y dos ermitas de ébano y marfil "en memoria de mi buena boluntad" (f. 86v).

UNED. REI, 8 (2020), pp. 9-39

ISSN 2340-9029 
en los años antes de su muerte, es además la que se encarga de llevar a cabo sus últimas voluntades, sobre todo aquellas más personales y afectivas recogidas en la memoria de 1683, cuando la condesa ya se encuentra enferma y probablemente en su lecho de muerte.

Son precisamente estas voluntades más personales y afectivas las que resultan bastante significativas en tanto que nos hablan de una familia femenina más extensa y no conectada a la condesa por lazos de consanguinidad, sino de amistad y/o servicio: se trata de criadas, jóvenes que la acompañan y asisten, alguna esclava, beatas y vecinas del barrio. Entre estas, además de sus familiares, reparte sus bienes materiales, creando así una conexión humana con sus posesiones más íntimas. Aunque el inventario completo de bienes no se ha conservado, en la documentación testamentaria se deja constancia de muchos de los objetos de su persona y casa y su distribución entre sus seres más allegados, ya fuera por lazos de sangre o no, evidenciando " $\mathrm{t}]$ he emotions and memories that willmakers invested in their belongings and how they divested themselves of them offer clues to the importance of their relationships with their legatees and their claim on continuing remembrance after death" (James, 2015: 279). ${ }^{33}$ No todos los miembros de esta comunidad femenina ocupan el mismo lugar en la jerarquía emocional de la condesa, como tampoco no todos sus familiares femeninos lo han hecho. De todas estas mujeres que la acompañan en su vida, las disposiciones de Guevara distinguen entre aquellas que ocupan posiciones propiamente de servicio y otras que han establecido con la condesa una relación mucho más cercana. De hecho, explica Blanco Carrasco,

Aunque alrededor de una casa trabajen o puedan trabajar un número importante de dependientes, no todos forman parte del grupo que atiende las necesidades más inmediatas o íntimas de los miembros de la familia. Estos son tratados como personas próximas, dignas de confianza y, en algunos casos,

\footnotetext{
${ }^{33}$ La repartición de bienes materiales (regalos, vestidos y menajes del hogar) que incluye el testamento se convierten así en "gendered markers which sustain(ed) and maintain(ed) a sense of spiritual and material affinity between the dead and the living community" (Helt, 2000: 189).
}

nos podemos encontrar un conjunto de personas unidas por el mismo cometido, con diferentes ocupaciones, cuyo principal signo diferenciador respecto de los demás viene dado por la cercanía simbólica a la familia. (2006: 45)

Entre las personas más próximas a la condesa destaca una joven de nombre María Fernández, "muchacha que he criado" y de unos 18 años, según dice al momento de testar en 1678 (f. 73v). La generosidad de la condesa con esta María Fernández es evidente en la cantidad de bienes económicos y materiales que le entrega, incluso dotándola para su casamiento (como dice en su memoria de 1683). Cabe señalar la importancia de dicha relación personal entre ellas, el aprecio y agradecimiento, al momento en que Guevara elige y dispone los objetos para la joven, ya que, además de lo que le podría haber dado en vida (ej. una arquilla de cedro larga), consisten en un cofre "de los mios", que ella misma puede elegir, un manto y vestido "de mi persona" y la mayor parte de las ropas de cama, así como dos colchones "de los que sirven en mi cama" (f. 73v). Para una mujer que no tuvo descendencia con ninguno de sus tres maridos, la condesa parece encontrar en la joven el cariño y el acompañamiento de lo que podría acercarse a ser una hija, de ahí su personal generosidad, aunque esta está marcada por el hecho de no ser de la misma sangre y de haber una diferencia social entre ellas.

De los demás "criados y criadas" de la casa, ese binomio inclusivo de un número amplio de sirvientes a los que la condesa recuerda en sus reparticiones, son las criadas las que salen mayormente beneficiadas: a "todas" las criadas, de escalera arriba y abajo, exige que se les dé una renta para ayudarlas a regresar a sus tierras y además, "dos camisas y unas enaguas de la ropa que de ordinario me sirven" (f. 86v).${ }^{34}$ Como Martínez Mira concluye de su investigación sobre los testamentos de mujeres en la Murcia del siglo XVI, era frecuente que las nobles repartieran parte de sus bienes, incluso objetos valiosos, entre miembros del servicio, con

${ }^{34}$ Previamente también en su testamento de 1678 , la condesa había distinguido entre los criados de escalera arriba y escalera abajo, a quienes en vez de dinero pide que se les permita quedarse con la librea que les ha dado en vida, una forma de mantener en perpetuidad un recuerdo de la casa a la que pertenecían (f. 79r).

UNED. REI, 8 (2020), pp. 9-39

ISSN 2340-9029 
objeto de agradecer el cariño y servicio prestado, hecho que "confirma que en la mayoría de los casos estas personas solían permanecer con los mismos amos durante toda su vida laboral" (2011a: 22). A pocos días de su defunción, en su memoria de 1683, son sus acompañantes femeninas, sirvientas y otras vecinas las que reciben de hecho exclusiva atención. Como es habitual en este tipo de documentación más próxima a la muerte, la condesa muestra un tipo de lenguaje igualmente menos burocrático y más emotivo. Por ejemplo, a Maruja, además darle para el luto (vestimenta o dinero para comprarla), pide que le den lo que sobre de su propia ropa para hacer "pañales" (f. 91r), "a Margarita mi cocinera, ademas de dos camisas mias, se le de el luto, y dos meses de racion como a las demas" (f. 91v), "a Ana Jacinta que es vieja se le de dicha limosna destas y un colchon de los de las criadas con una manta" (f. 91v), "a isabelica un guardapies ... a muslo para que se lo acorten y que avisen a su padre que venga a por ella” (f. 91v) y a Ana Cano, además de lo indicado en las mandas de su testamento de 1678 (que era un vestido porque llevaba muy poco tiempo con ella), se le dé lo que a las otras criadas y además "100 ducados de sus bienes por lo bien que me ha servido y me acompaña” (f. 91r). Toda esta parafernalia testamental definitivamente nos revela una Guevara que aprecia y recompensa generosamente a sus empleadas y compañeras de viaje en vida, ya que, como indica Martínez Mira, a pesar de las distancias marcadas por el estatus de cada una de ellas, "el protocolo jerárquico" era compatible "con una notable corriente afectiva entre ambas" (2011a: 22). Ahora bien, con tales actos Guevara no solo proclama su generosidad, sino que también recuerda la distancia que las separa socialmente y le da autoridad, ya que con sus actos dispositivos

while certainly revealing compassionate feelings of appreciation and generosity, might have also created a bounded space in which the social status of the employer was reinforced and at the same time the social inequality of the relationship between servants and mistresses was reproduced, thus indirectly and symbolically placing mistresses in a dominating position" (Benadusi, 2004: 817). ${ }^{35}$

${ }^{35}$ Helt se refiere a este doble efecto del acto de donación y repartición de bienes entre la
Destaca en este sentido la relación de las señoras con sus esclavos y esclavas, con los que suelen tener una consideración particular, preocupándose por su futuro, dejándoles dinero e incluso liberándolos (Martínez Mira, 2011a). Guevara, por ejemplo, pone una especial atención en María Antonia, "una mulatilla de hedad de catorçe años que la he criado" (f. 86r), por la que pide que, a su costa, sus hermanas la acepten en una de sus casas en la Villa de Madrid o si no le encuentren casa de servicio en Valladolid (f. 84r), y a quien deja: 100 ducados de vellón en renta hasta que tome estado, "dos colchones de los mios, quatro savanas y dos almuadas, una manta y una colcha de lo mejor que hubiere," un cofre, una arquilla (f. 84r), a los cuales en el codicilo añade "un manto y una basquiña" [f. $762 v]$ ); pero lo más importante, "por lo bien que la dicha Mulatilla me ha servido y el cariño de la criança, le doy la livertad en toda forma y la encargo me encomiende a Dios" (f. 86r). Guevara "desviste su casa y su cuerpo" y los reparte acorde a su relación afectiva y social, convirtiendo después de su muerte tanto los objetos que la rodean como a las personas que los reciben en "extensions of their personal identity, status, and wealth" (James, 2015: 232). La proyección de Guevara se imprime así en todo aquello que ha tocado y manejado en su vida, ya sean personas, objetos o propiedades, consiguiendo memorializar una imagen particular de quien es, quien quiere ser y cómo quiere ser recordada.

A manera de conclusión, por tanto, se podría decir que la imagen de María de Guevara que nos llega a nosotros es la de una mujer independiente, orgullosa de su linaje, protectora de sus títulos y propiedades, perteneciente a una nobleza local pero con fuertes vínculos cortesanos, leal a una ideología nobiliaria bastante tradicional que quiere revivir nostálgicamente el esplendor pasado de su familia, al tiempo que es una mujer consciente de su género sexual y del valor de la participación de la mujer en la escritura de la historia. Definitivamente lo que revela en

comunidad, el de fortalecer los lazos afectivos así como el de marcar la jerarquía social entre la donante y los que reciben las donaciones; en sus propias palabras, estos actos de memoria sirven no solo "to reinforce the social hierarchy but also to sustain the horizontal interdependencies that marked both the place of the living and the dead in local structures of family, social network and community" (Helt, 2000: 205).

UNED. REI, 8 (2020), pp. 9-39

ISSN 2340-9029 
sus últimas voluntades, como otras mujeres nobles de la época, "is valuable information about how their lives were structured in terms of power, moral principles, attitudes towards afterlife, how all this shapes social behavior” (Martínez Mira, 2011b: 103). La proyección espacial, material y emocional que Guevara (re)construye en su testamento confirma la forma en que se auto-percibe como una noble digna de su posición política, social y económica y, sobre todo, responsable de la misma como su cabeza. Junto con sus peticiones y sus textos políticos, la documentación testamentaria se convierte en su mayor legado, el cual tiene por objetivo representar a María de Guevara, su nombre y su linaje para la historia, instituyéndola legítimamente en una posición de autoridad que, con sus palabras y sus acciones, imprime no solo en la memoria privada de la familia sino en la de toda una comunidad.

Recibido: 06/02/2020

Aceptado: 10/03/2020

\section{Referencias bibliográficas}

Atienza Hernández, Ignacio (2012), "Mujeres y cultura nobiliaria en el siglo de oro hispano: doña María de Guevara, Condesa de Escalante", en Amparo Serrano de Haro Soriano y Esther Alegre Carvajal (coords.), Retrato de la mujer renacentista, Madrid: UNED, pp. 165-88.

Ballesteros Robles, Luis (1912), Diccionario biográfico matritense, Madrid: Ayuntamiento.

Baranda, Nieves (2005), "Lecturas de damas aristócratas en el siglo XVII", Cortejo a lo prohibido. Lectoras y escritoras en la España moderna, Madrid: Arco/Libros, pp. 35-64.

Barbeito Carneiro, María Isabel (1986), “María de Guevara”, Escritoras madrileñas del siglo XVII. Estudio bibliográfico-crítico. Madrid: Universidad Complutense de Madrid, vol. 2, pp. 297-307.

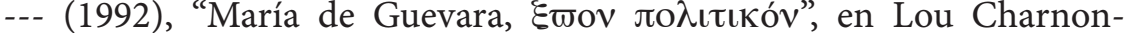
Deutsch (ed.), Estudios sobre escritoras hispánicas en honor de Georgina Sabat-Rivers, Madrid: Castalia, pp. 62-78.

Benadusi, Giovanna (2004), "Investing the Riches of the Poor: Servant Women and Their Last Wills", The American Historical Review, 109.3, pp. 805-826.

BIESES. Bibliografía de autoras españolas. <http://www.bieses.net/> [Consulta: 15/10/2019].

Blanco Carrasco, José Pablo (2006), “Criados y servidumbre en España durante la Época Moderna. Reflexiones en torno a su volumen y distribución espacial a finales del Antiguo Régimen", Investigaciones Históricas, 36, pp. 41-80.

Caro Baroja, Julio (1981), "Una dama corajuda y arbistrista", Vidas poco paralelas (con perdón de Plutarco). Madrid: Turner, pp. 69-87.

Cruz, Anne J. (2019), “'Si no fuere tu hija ilustre’: Women Writers' Social Status in Early Modern Spain", Cuadernos de Historia Moderna, 44.2, pp. 345-362.

Esteves Santamaría, María del Pilar (2017), "Prácticas testamentarias en el Madrid del siglo XVI: Norma y Realidad", en IX Jornadas Científicas sobre Documentación (Madrid, 2010): La muerte y sus testimonios escritos [en línea]. <https://www.ucm.es/data/cont/docs/446-2013-08-22-02_ esteves\%20santamaria.pdf> [Consulta: 16/10/2019].

Fantoni y Benedí, Rafael (2000), “Los Alagón, Condes de Sástago”, Hidalguía, 280-281, pp. 555-575.

García Fernández, Máximo (1996), Los castellanos y la muerte. Religiosidad y comportamientos colectivos en el Antiguo Régimen, Valladolid: Estudios de Historia Junta de Castilla y León.

Guerrero Navarrete, Yolanda (2016), “Testamentos de mujeres: Una fuente para el análisis de las estrategias familiares y de las redes de poder formal e informal de la nobleza castellana", Studia historica. Historia medieval, 34, pp. 89-118.

UNED. REI, 8 (2020), pp. 9-39

ISSN 2340-9029 
Guevara, Antonio de (2000), Libro primero de las epístolas familiares, Alicante: Biblioteca Virtual Miguel de Cervantes. <http://www.cervantesvirtual.com/obra/libro-primero-de-las-epistolas-familiares--2/> [Consulta 14/4/2020].

Guevara, María de (1654). Memorial de la casa de Escalante y servicios de ella al Rey Nuestro Señor, Valladolid: s.n., f. 225r-251v. Biblioteca Universitaria de Salamanca, 2282. [También en AHNSN: Osuna, C.2722, D.10].

--- (1656), Memorial de la casa de Escalante y servicios de ella al Rey Nuestro Señor, Valladolid, Biblioteca Nacional de España [BNE], V-C 5713.

--- (1663), Tratado y advertenzias hechas por una muger celossa del vien de su rey y corrida de parte de España, en Papeles referentes a las justas literarias y a la Academia de Buen Retiro, Madrid, BNE, Ms 12270, pp. 401-432.

--- (1664), Desengaños de la corte y mujeres valerosas, s.l.: s.n. BNE, $\mathrm{R} / 4.496$.

--- (2007), Warnings to the Kings and Advice on Restoring Spain, Nieves Romero-Díaz (introd. y ed. bilingüe), Chicago/ Londres: University of Chicago Press.

Helt, J. S. (2000), "Women, Memory and Will-Making in Elizabeth England", en Bruce Gordon y Peter Marshall (eds.), The Place of Death: Death and Remembrance in Late Medieval and Early Modern Europe, Cambridge: Cambridge UP, pp. 188-205.

Hernández, Rosilie (2011), “The Politics of Exemplarity: Biblical Women and the Education of the Spanish Lady in Martín Carrillo, Sebastián de Herrera Barnuevo, and María de Guevara”, en Anne J. Cruz y Rosilie Hernández (eds.), Women's Literacy in Early Modern Spain and the New World, Burlington, VT: Ashgate, pp. 225-241.

James, Susan E (2015), Women's Voices in Tudor Wills, 1485-1603: Authority, Influence and Material Culture, Burlington, VT: Ashgate.
Lacarra, María Jesús (2009), "La última etapa en la vida de Leonor López de Córdoba: de las Memorias a sus disposiciones testamentarias", Revista de Literatura Medieval, 21, pp. 195-218.

Langle de Paz, Teresa (2003), “En busca del paraíso ausente: 'mujer varonil' y 'autor femenil' en una utopía feminista inédita del siglo XVII español”, Hispania, 86.3, pp. 463-473.

López Cordón, María Victoria (2007). “De escritura femenina y arbitrios políticos: la obra de doña María de Guevara”, Cuadernos de Historia Contemporánea, 1, pp. 151-164.

Lucena Salmoral, Manuel (1966), Presidentes de capa y espada (16281654), tomo 2 de Nuevo Reino de Granada. Real Audiencia de Granada: Presidentes de Capa y Espada, vol. 3 de Historia extensa de Colombia, Bogotá: Ediciones Lerner.

Martínez Gil, Fernando (1993), Muerte y sociedad en la España de los Austrias, Madrid: Universidad Castilla - La Mancha.

Martínez Mira, María Isabel (2011a), "La mujer a través de los testamentos del siglo XVI en protocolos notariales del Archivo Provincial de Murcia”, Mvrgetana, 124.62, pp. 9-32.

--- (2011b), “Female Testaments as Social Discourse: A Textual Analysis Under a Critical Discourse Analysis Approach", Mediterranean Journal of Social Sciences, 2.2, pp. 101-110.

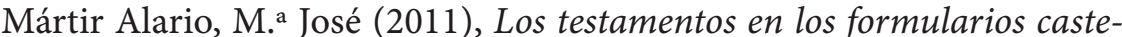
llanos del siglo XVI, Granada: Servicio de Publicaciones Universidad de Granada.

Robles, Tania (2012), "María de Guevara: consciencia histórica y política exterior", en Elena Hernández Sandoica (ed.), Política y escritura de mujeres, Madrid: Abada Editores, pp. 13-132.

Rojo, Anastasio (s.a.), “Testamento e inventario de doña Beatriz de Ribamontan, viuda de Martin Ortin de Matienzo secretario de estado. Valladolid, 1 de junio de 1635", Real Biblioteca de Investigadores. Anastasio 
Rojo Vega. <https://investigadoresrb.patrimonionacional.es/node/7017> [Consulta: 23/01/2019].

Romero-Díaz, Nieves (2007), “Introduction”, en María de Guevara, Warnings to the Kings and Advice on Restoring Spain, Chicago y Londres: University of Chicago Press, pp.1-41.

--- (2009), “El discurso reformista de Luisa de Padilla y María de Guevara ante las novedades y vicios de una sociedad en crisis", en Enrique García Santo-Tomás (ed.), Materia crítica: formas de ocio y de consumo en la cultura áurea, Madrid: Iberoamericana, pp. 59-75.

--- (2017), "Women and Power", en Nieves Baranda y Anne J. Cruz (eds.), The Routledge Research Companion to Early Modern Spanish Writers, Londres y Nueva York: Routledge, pp. 237-52.

--- (2018), “Mujeres y poder”, en Nieves Baranda y Anne J. Cruz (eds.), Las escritoras españolas de la edad moderna, (1500-1700). Historia y guía para la investigación, Madrid: UNED, pp. 377-402.

Saavedra y Ladrón de Guevara, Martín (1658), Memorial al rey nuestro señor por don Martin de Saavedra Ladrón de Guevara, Madrid, AHNSN, Osuna: C. 3363, D. 9.

--- (1665), Memorial al Rey Nuestro Señor, Madrid, BNE, 2/54937.

--- (1683), Memorial al rey nuestro Señor, Zaragoza: Por los herederos de Diego Domer. BNE, 2/65425.

Serrano y Sanz, Manuel (1903-1095), Apuntes para una biblioteca de escritoras españolas desde 1401 a 1833, Madrid: Sucesores de Rivadeneyra, 4 vols. (reimp. 1975).

Tabernero, Cristina (2016), "El testamento como género discursivo en la documentación peninsular (de la Edad Media al siglo XVIII)", Onomázein. Revista semestral de Lingüística, Filología y Traducción, 34, pp. 70-85.

Uhagón, Francisco R. de (1901), "El Santo Cristo de María Estuart”, Revista de Archivos, Bibliotecas y Museos, 5.2-3, pp. 102-116.
Valdés Pozueco, Catarina (2010), "Las últimas voluntades de Calderón de la Barca: un modelo de testamento en la Edad Moderna”, Anuario Jurídico y Económico Escurialense, 43, pp. 457-482.

Valladares de Sotomayor, Antonio de (1790), Semanario erudito, que comprehende varias obras inéditas, críticas, morales, instructivas, politicas, históricas, satíricas, y jocosas de nuestros mejores autores antiguos y modernos, Madrid: Por don Antonio Espinosa, t. XXXI.

Vilar, Enriqueta y Lourdes Kuethe (2006), "La idea de nobleza y el más allá: advocaciones religiosas en los testamentos", Boletín de la Real Academia Sevillana de Buenas Letras, 34, pp. 213-233. 